\section{Commentary: The conundrum of cerebral malperfusion in aortic dissection}

Marco A. Zenati, MD

The International Registry of Acute Aortic Dissection (IRAD) investigators have provided a detailed analysis of 2402 patients over a 7-year period ending in 2017 in whom cerebral malperfusion (CM) was defined by clinical presentation at the time of type A acute aortic dissection (TAAAD) and was accompanied by clear evidence of neurologic deficit on physical examination. ${ }^{1}$ The authors boldly conclude that: "it is reasonable to perform surgery on patients with CM ... as in-hospital outcomes are acceptable in this critically ill patient population." While this conclusion is indeed supported by the short-term data presented, a word of caution in interpreting the results is still necessary.

CM was defined in IRAD based on preoperative symptoms alone, rather than classified based on computed tomography findings, which are usually ubiquitously available in these patients. A "hard" imaging-based diagnosis would have significantly enhanced the quality of the data presented here, but unfortunately it was not available to the IRAD investigators.

Since only tertiary referral centers participate in IRAD, a significant number of patients with TAAD with $\mathrm{CM}$ who either died at the local emergency department or community hospital or during emergency transfer were not included in this analysis. Therefore, the patients who were ultimately included in this study are a subset from a larger unknown pool that selfselected themselves out as survivors since the time of the original presentation. The authors also acknowledge that the time in hours from the neurologic symptom presentation (eg, syncope, transient neurologic attack, etc) was not reliably collected in IRAD, although it would have been invaluable to make inferences regarding mortality and recovery rates.

\footnotetext{
From the Division of Cardiac Surgery, Veterans Affairs Boston Healthcare System and Department of Surgery, Brigham and Women's Hospital, Harvard Medical School, Boston, Mass.

Disclosures: Author has nothing to disclose with regard to commercial support.

Received for publication Nov 23, 2019; revisions received Nov 23, 2019; accepted for publication Nov 25, 2019; available ahead of print Dec 12, 2019.

Address for reprints: Marco A. Zenati, MD, Division of Cardiac Surgery, Veterans Affairs Boston Healthcare System, 1400 VFW Parkway, Boston, MA 02132 (E-mail: Marco_Zenati@hms.harvard.edu).

J Thorac Cardiovasc Surg 2021;161:1721

0022-5223/\$0.00

Published by Elsevier Inc. on behalf of The American Association for Thoracic Surgery

https://doi.org/10.1016/j.jtcvs.2019.11.103
}

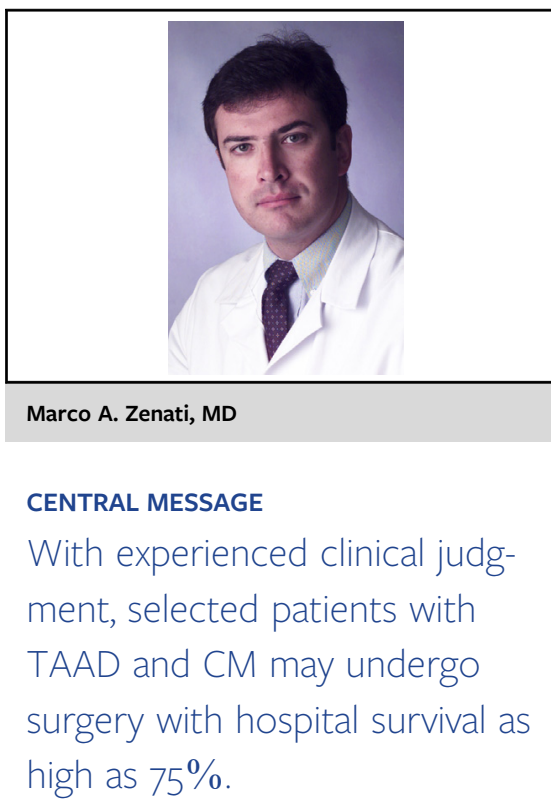

The axillary artery cannulation approach was surprisingly underused in the CM cohort $(35.1 \%$ vs $43.8 \%)$ in this study, and this difference may have contributed to inadequate cerebral protection in the CM group, as this technique allows superior delivery of antegrade cerebral perfusion, especially during prolonged periods of deep hypothermic circulatory arrest.

The authors report that the rate of cerebrovascular accident/coma was greater in the CM group $(17.5 \%$ vs $7.2 \%$ and $0.3 \%$ vs $2.6 \%$, respectively) and that survival was lower in the CM cohort $(62.6 \%$ vs $81.3 \% ; P<.001)$ at 1 year. Unfortunately, not all centers provided follow-up data to 1 year, and the numbers at risk are insufficient to support a long-term conclusion. Furthermore, the authors did not report outcomes on patients with TAAD and CM who did not undergo surgical repair.

A more tempered conclusion of this otherwise-laudable IRAD study could be that, with experienced clinical judgment, selected patients with TAAD and CM may undergo surgery with hospital survival as high as $75 \%$.

Despite this welcome contribution by the IRAD investigators, the conundrum offered by $\mathrm{CM}$ in TAAD is going to remain and vex cardiac surgeons trying to make the best decision for their patients, often with incomplete information and always under considerable time pressure, in the years to come.

\footnotetext{
Reference

1. Ibrahim Sultan I, Bianco V, Patel HJ, Arnaoutakis GJ, Di Eusanio M, Chen EP, et al. Surgery for type A aortic dissection in patients with cerebral malperfusion: results from the International Registry of Acute Aortic Dissections. J Thorac Cardiovasc Surg. 2021;161:1713-20.e1.
} 